\title{
Statistical analysis of main and interaction effects during the removal of BTEX mixtures in batch conditions, using wastewater treatment plant sludge microbes
}

\author{
${ }^{1}$ E. R. Rene, ${ }^{2}$ M. S. Jo, S. H. Kim, ${ }^{2 *}$ H. S. Park \\ ${ }^{1}$ University of La Coruña, Department of Chemical Engineering, Faculty of Sciences, Campus da Zapateira, \\ E-15071-La Coruña, Spain \\ ${ }^{2}$ Department of Civil and Environmental Engineering, University of Ulsan, San-29 Moogu-2 Dong, Nam-Gu, \\ Ulsan, South Korea
}

Received 29 November 2006; revised 26 February 2007; accepted 5 March 2007; available online 20 March 2007

\begin{abstract}
Biodegradation has proved to be a versatile technique to remediate benzene, toluene, ethyl benzene and xylene (BTEX) mixtures in contaminated soil and groundwater. In this study, a mixed microbial culture obtained from a wastewater treatment plant was used to degrade liquid phase BTEX, at initial concentrations varying between 15 to $75 \mathrm{mg} / \mathrm{l}$. Experiments were conducted according to the $2^{\mathrm{k}-1}$ fractional factorial design to identify the main and interaction effects of parameters and their influence on biodegradation of individual BTEX compounds in mixtures. The removal efficiencies of these compounds varied between 2 to $90 \%$ depending on the concentration of other compounds and also on their interaction effects. A statistical interpretation of the results was done based on the Fishers variance ratio $(\mathrm{F})$ and probability $(\mathrm{P})$ values. Though all the main effects were found significant $(\mathrm{P}<0.05)$ at the $5 \%$ confidence level, the interactions between benzene and toluene and benzene and xylene concentrations were also found to be statistically significant and play a major role in affecting the total BTEX removal.
\end{abstract}

Key words: BTEX mixture, biodegradation, fractional factorial design, removal efficiency, statistical analysis

\section{INTRODUCTION}

Benzene, toluene, ethyl benzene and xylene collectively known as (BTEX) are widely used as industrial solvents for organic synthesis and are the major products of petroleum and fine chemical industries. They are generated from a wide variety of industrial sources, and a majority of them arise from fine chemical and petrochemical industries. They frequently enter the air, soil and water environment through leakages from underground storage tanks, pipelines, accidental spills, improper practices and leaching landfills (Yeom and Yoo, 1999). The BTEXs make up the alkylbenzenes and constitute up to about $18 \%(\mathrm{w} / \mathrm{w})$ in a standard gasoline blend. BTEXs are considered to be very important since they contribute generously to global environmental effects such as ozone layer depletion, green house effects and acid rain (Jenkin and Chemitshaw, 2000; Burgess, et al., 2001). Even at low concentrations, BTEX can cause damage to the liver and kidney and paralyze the central nervous system (Martin, et al., 1998; Murata,

\footnotetext{
*Corresponding author, Email: parkhs@ulsan.ac.kr

Tel.: +82 52259 1050; Fax: +82 522210152
}

et al., 1999; Bahrani and Edwards, 2006). The contamination of soils and aquifers with petroleum hydrocarbon is a major environmental problem. Generally BTEX compounds are often encountered as mixtures rather than as a single compound and the fate of these compounds is often strongly controlled by microbial activity (Schwarzenbach, et al., 1993). It has been proved earlier that, biodegradation is a versatile treatment option to remove BTEX at various concentrations using indigenous or acclimatized microbial species.

Earlier, significant research has been conducted using pure cultures for degrading and studying the kinetics of BTEX compounds, but they usually could not degrade all compounds simultaneously and efficiently. Hence, most of the studies on the biodegradation of BTEX compounds have primarily been carried out with mixed cultures acclimatized to specific compounds in batch and continuous systems (Alvarez and Vogel, 1991; Shim and Yang, 1999; Rene, et al.,2001; Gusmao, et al., 2006). A few studies on the biodegradation of mixtures of BTEX compounds have also been reported. Kelly, et 
al. (1996) studied the kinetics of BTX biodegradation in batch systems using a mixed consortium from a contaminated soil and observed substrate disappearance in the order: toluene $>$ benzene $>$ xylene. Chang, et al. (1993) observed in batch studies using Pseudomonas fragi that the rate of degradation of either benzene or toluene in the presence of other substrate was slower than the degradation rate of either substrate alone. Arvin, et al. (1989) investigated benzene degradation in the presence of toluene, $o$-xylene and a number of poly nuclear aromatic hydrocarbons. Their study reveals that in the presence of either toluene or $o$-xylene, benzene degradation was stimulated. Oh, et al. (1994) investigated the degradation of $\mathrm{B}, \mathrm{T}$ and $p$-X individually and in mixtures by a mixed consortium and a Pseudomonas species. They observed benzene and toluene degradation but not $p$-xylene as individual substrate, while in mixtures competitive inhibition and cometabolic degradation were observed.

In this paper, BTEX biodegradation as mixtures was studied using a mixed bacterial consortium (mixed culture) in free (suspended) cell systems. The effect of substrate concentration on cell growth has been examined. Experiments were carried out at different initial concentrations of BTEX corresponding to total BTEX concentrations varying between 60 and $300 \mathrm{mg} / \mathrm{L}$. These experiments were conducted as per the experimental plan outlined by fractional factorial design of experiments to identify the main and interaction effects during BTEX removal. The results were statistically interpreted and presented in this paper. This research have been done in Environmental Pollution Control Laboratory, University of Ulsan, South Korea during February 2006 to July 2006.

\section{MATERIALS AND METHODS}

Microorganism and media composition

The mixed bacterial consortium was obtained from the effluent treatment plant of a chemical industry located in Ulsan, South Korea. The mineral salt medium (MSM) used in this study had the following composition: $\left(\mathrm{NH}_{4}\right)_{2} \mathrm{SO}_{4}-5 \mathrm{~g} / \mathrm{L}, \mathrm{K}_{2} \mathrm{HPO}_{4}-2 \mathrm{~g} / \mathrm{L}$, $\mathrm{MgSO}_{4} .7 \mathrm{H}_{2} \mathrm{O}-0.2 \mathrm{~g} / \mathrm{L}, \mathrm{KH}_{2} \mathrm{PO}_{4}-1 \mathrm{~g} / \mathrm{L}, \mathrm{CaCl}_{2} .2 \mathrm{H}_{2} \mathrm{O}-$ $13.2 \mathrm{mg} / \mathrm{L}, \mathrm{FeSO}_{4} \cdot 7 \mathrm{H}_{2} \mathrm{O}-10 \mathrm{mg} / \mathrm{L}, \mathrm{NaCl}-5 \mathrm{~g} / \mathrm{L}$, Yeast extract - $0.2 \mathrm{~g} / \mathrm{L}$ and trace elements - $2 \mathrm{~mL} / \mathrm{L}\left(\mathrm{MoO}_{3}\right.$ $1 \mathrm{mg} / \mathrm{L}, \mathrm{ZnSO}_{4} .7 \mathrm{H}_{2} \mathrm{O}-7 \mathrm{mg} / \mathrm{L}, \mathrm{CuSO}_{4} .5 \mathrm{H}_{2} \mathrm{O}-0.5 \mathrm{mg} / \mathrm{L}$, $\mathrm{H}_{3} \mathrm{BO}_{3}-1 \mathrm{mg} / \mathrm{L}, \mathrm{CoCl}_{2} \cdot 6 \mathrm{H}_{2} \mathrm{O}-6 \mathrm{mg} / \mathrm{L}, \mathrm{NiSO}_{4} \cdot 6 \mathrm{H}_{2} \mathrm{O}-1 \mathrm{mg} /$ $\mathrm{L})$. All chemicals used were of analytical grade. The $\mathrm{pH}$ of the media was maintained at $7 \pm 0.1$.

\section{BTEX removal experiments}

Batch removal experiments were conducted by varying individual BTEX concentrations between 15$75 \mathrm{mg} / \mathrm{L}$ according to the statistically significant fractional factorial design (Table 1), in $500 \mathrm{~mL}$ glass bottles (working volume $300 \mathrm{~mL}$ ) fitted with appropriate toggle valve based screw caps. These valves were made of Teflon that housed needles to collect headspace BTEX and biomass in suspension. BTEX was directly injected to this working volume corresponding to different initial concentrations and after water-air equilibration $3 \%$ of the microbial suspension was added. The resulting BTEX containing MSM was incubated in a rotary shaker at $150 \mathrm{rpm}$ and maintained at ambient temperatures $\left(28-30^{\circ} \mathrm{C}\right)$. Samples collected at regular intervals were analyzed for biomass and residual BTEX concentration.

\section{Analytical methods}

Free cell concentrations was determined by measuring the optical density (OD at $660 \mathrm{~nm}$ ) using a UV-visible spectrophotometer (Shimadzu UV-Min 1240, Japan) and reading from a standard calibration plot between $\mathrm{OD}_{660}$ and cell dry weight. The concentrations of BTEX in liquid phase were determined from the waterair partition coefficient values (Mackay and Shiu, 1981), and by the procedure described in Prenafeta-Boldu, et al. (2002). Head space BTEX measurements were done by injecting $100 \mu$ l headspace samples collected in gastight syringe (Hamilton Co, Reno, Nevada, USA) into a DS-6200 Gas Chromatograph fitted with a HP-FFAP capillary column and flame ionization detector. Nitrogen was used as the carrier gas at a flow rate of $20 \mathrm{~mL} / \mathrm{min}$. The temperatures of the injection port, oven and detection port were 250,80 and $250{ }^{\circ} \mathrm{C}$.

\section{Statistical design of experiments}

Experiments with different concentrations of BTEX were conducted using the experimental design obtained by $2^{\mathrm{k}-1}$ fractional factorial design. Fractional factorial designs are two level designs (low and high values of the factor), which includes only a fraction of the total trial that comprise a full factorial design (Box and Hunter, 1978; Montgomery, 1991). It consists of $2^{\mathrm{k}-1}$ runs (trials), where ' 2 ' represent the two levels of the factor and ' $k$ ' is the total number of factor. Moreover, when high order interactions are negligible, reasonable information on the main effects and low order interactions may be obtained by running only a fraction of the complete factorial design. Hence, $2^{(4-1)}$ design is 
a fraction of the $2^{4}$ full fractional designs that consist of 8 runs instead of 16 with 2 center-point replicates. Statistical analysis was performed with the software Minitab (Version 12.2, PA, USA).

\section{RESULTS}

Batch biodegradation tests were conducted with wastewater treatment plant sludge microbes, according to the 10 experiments designed by fractional factorial design (Table 1). The cumulative BTEX removed was calculated as follows

TotalBTEX removal $=\frac{(\text { Total }-B T E X)_{\text {initial }}-(\text { Total }-B T E X)_{\text {final }}}{\text { Total }-B T E X_{\text {initial }}} \times 100$

The biomass growth profile and substrate utilization pattern observed for mixed culture while utilizing BTEX as the sole carbon source is shown in Fig. 1. The biomass growth showed a typical microbial growth pattern with a short lag phase, a growth phase and a stationary phase. However the removal pattern and extent of growth were also a function of the initial concentration of different substrates. Within the first 10 hours of experimentation, a rapid decline in the concentrations of individual substrates was noticed with a sharp increase in the cell growth. During Expt-1, at low concentrations of BTEX, ethyl benzene was better removed at $68 \%$ by the microbes in comparison to B $(4.7 \%)$, $\mathrm{T}(18.7 \%)$ and $\mathrm{X}(4 \%)$. However, when the concentration of benzene and xylene was increased to $75 \mathrm{mg} / \mathrm{L}$, the removal of toluene decreased to $14 \%$, while no change in the removal of ethyl benzene was noticed. Increasing the concentrations of toluene and xylene, decreased the removal of benzene, while it synergistically increased the removal of other compounds. TEX was removed at 46, 45 and $72 \%$ respectively. Similarly, when the concentration of benzene was increased (Expt-4), a marginal decrease in

Table 1: Concentrations of individual BTEX compounds for different experiments

\begin{tabular}{|c|c|c|c|c|}
\hline \multirow{2}{*}{ Expt No } & \multicolumn{3}{|c|}{ Concentration of individual substrates, } & \multirow{2}{*}{$\begin{array}{c}\mathrm{mg} / \mathrm{L} \\
\mathrm{X}\end{array}$} \\
\hline & B & $\mathrm{T}$ & E & \\
\hline 1 & 15 & 15 & 15 & 15 \\
\hline 2 & 75 & 15 & 15 & 75 \\
\hline 3 & 15 & 75 & 15 & 75 \\
\hline 4 & 75 & 75 & 15 & 15 \\
\hline 5 & 15 & 15 & 75 & 75 \\
\hline 6 & 75 & 15 & 75 & 15 \\
\hline 7 & 15 & 75 & 75 & 15 \\
\hline 8 & 75 & 75 & 75 & 75 \\
\hline 9 & 45 & 45 & 45 & 45 \\
\hline 10 & 45 & 45 & 45 & 45 \\
\hline
\end{tabular}

the removal of TEX was observed, while benzene removal increased to $80 \%$. In expt-8, the highest levels of concentrations of individual BTEX compounds (75 $\mathrm{mg} / \mathrm{L}$ ), the removal of BTEX were 58, 84, 89 and 80\% respectively. Maximum biomass growth was observed in Expt-4, when benzene concentration was $75 \mathrm{mg} / \mathrm{L}$. Increasing the concentrations of benzene, not only increased benzene removal but also stimulated better biomass growth. The total BTEX removals varied between 23.7 to $78 \%$ and this value principally depended on the low and high levels of concentrations of individual BTEX compounds in the quaternary mixture. It is evident from Fig. 2 (main effects plot), that the total BTEX removal increased with increased in concentrations of individual BTEX compounds from low to high levels. However the biomass growth was found to vary depending on the initial concentrations of BTEX.
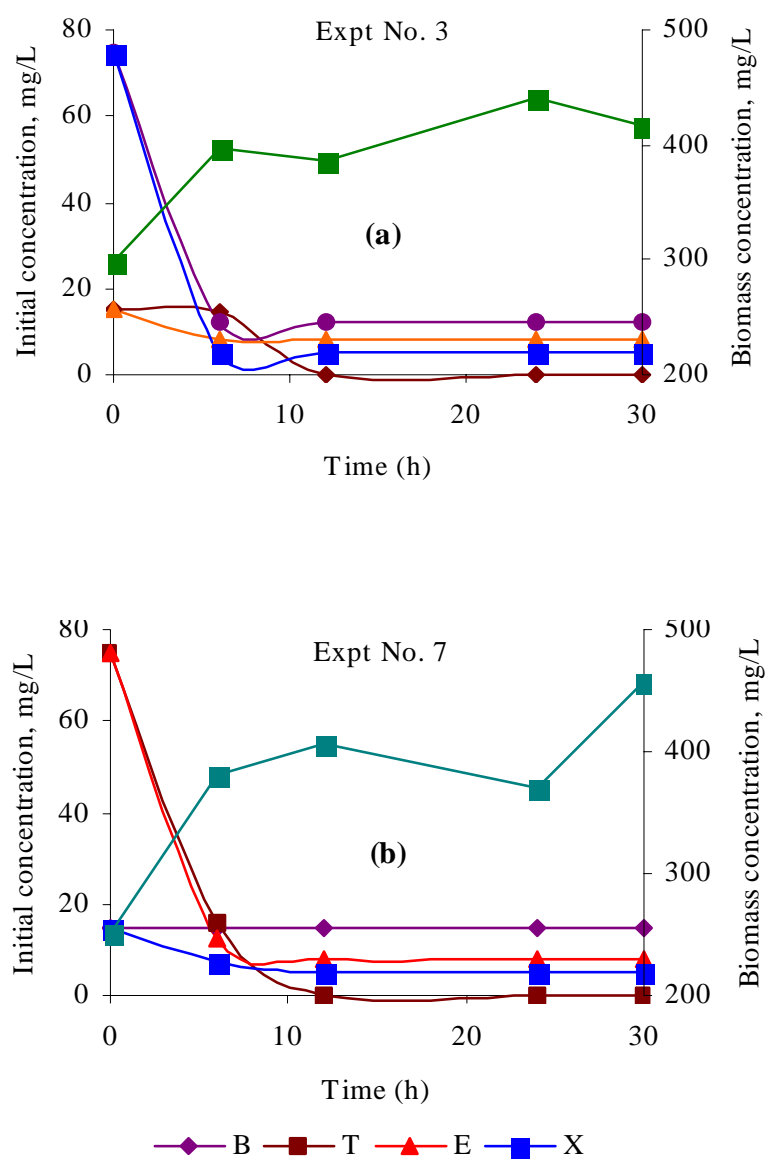

Fig 1: Substrate utilization and biomass growth profile of mixed cultures utilizing BTEX as the primary carbon source (a) Expt-3 (b) Expt-7 


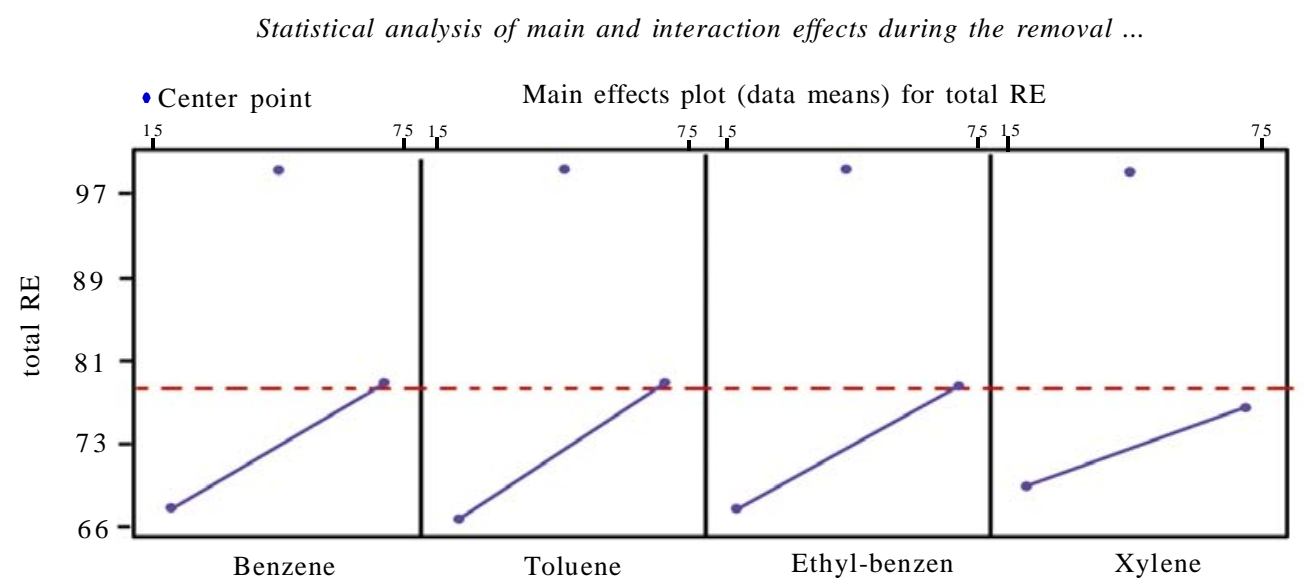

Fig. 2: Main effect plot of variables on the total BTEX removal by mixed cultures

(Units: BTEX concentration, mg/L; Total-RE, \%)

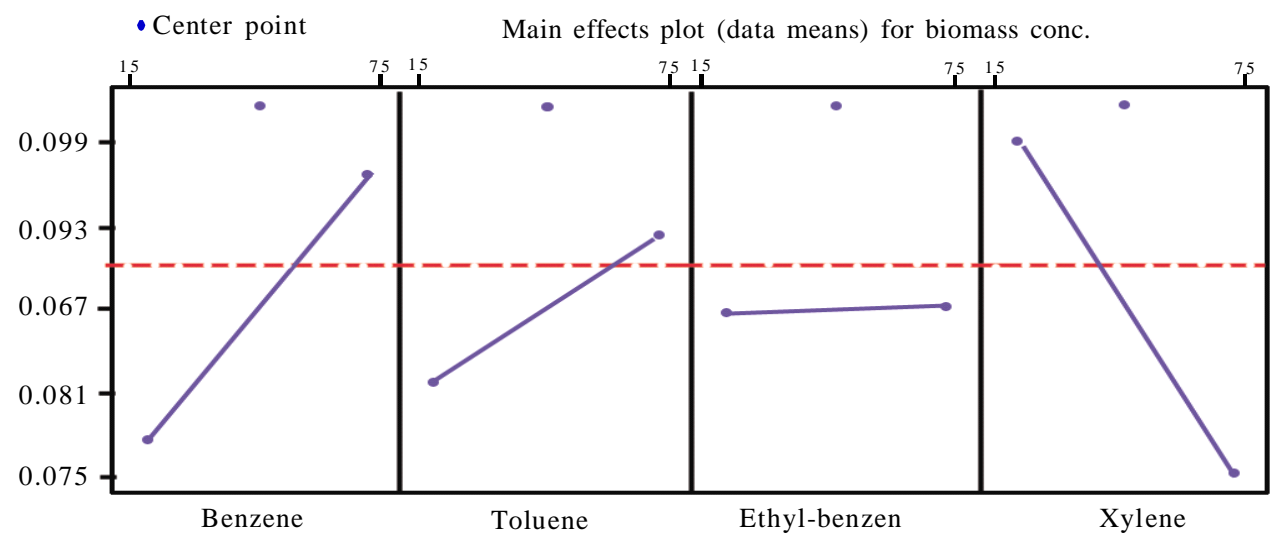

Fig. 3: Main effects plot for maximum biomass growth of mixed cultures

(Units: Biomass concentration, g/L and BTEX, mg/L)

It can be elucidated from Fig. 3, that increasing the concentrations of BT stimulated biomass growth, while a severe antagonistic effect was noticed, when xylene concentrations were increased from low to high levels in the mixture. The presence of ethyl benzene did not affect the biomass growth pattern.

\section{DISCUSSION AND CONCLUSIONS}

The prime reason for antagonistic effects during BTEX degradation in mixtures can be attributed to competitive inhibition (Chang, et al., 1993; Oh, et al., 1994; Bielefeldt and Stensel, 1999), toxicity (Haigler, et al., 1992) and the formation of toxic intermediates by non-specific enzymes (Bartels, et al., 1984). The interaction plots (Fig. 4) showed that, at high levels of toluene and xylene concentrations, and at low levels of benzene and xylene, there exists interaction. All other interactions were in significant within the range of BTEX concentrations studied. This can also be substantiated by the ANOVA table given in given in Table 2 and ' $t$ ', ' $P$ ' values given in Table 3. In general, the Fischer's ' $F$ ' value with a low probability ' $P$ ' value indicates high significance of the regression model (Khuri and Cornell, 1987). The students ' $t$ ' test can be used as a tool to check the significance of the regression coefficient of the parameter, while ' $P$ ' values signify the pattern of interaction among the factors. The larger the value of $t$ and smaller the value of $P$, the more significant is the corresponding coefficient term (Montgomery, 1991). High F values for main effects (5000) with low $P$ values (0.010) suggests that the individual effects were significant than the 2 way interaction effects (F-284.85, P-0.044). Among the main effects, benzene and toluene concentrations affected the total BTEX removal $(t-99,85.75, P-0.006,0.007)$, while the interactions between benzene and toluene concentrations were insignificant $(t-5, P-0.126)$. 
The mixed wastewater treatment plant sludge microbes were able to grow well in the mineral salt media with BTEX as the sole carbon source. The culture showed different utilization pattern at different initial concentrations of BTEX compounds in mixtures. At the highest concentration range tested, the individual BTEX removal efficiencies were 58, 84, 89 and 81\% respectively. Preferential utilization of substrates was observed depending on their toxicity and initial oxidation mechanisms. The synergistic and antagonistic interactions were elucidated statistically through their $\mathrm{F}$ and $\mathrm{P}$ values. Increasing the concentrations of BTEX from low to high levels stimulated the total BTEX removal. However, their individual removal efficiencies showed a varied response depending on the initial concentrations of other substrates. The results from this study further delineate that the main effects of the variables had a significant effect in increasing the total BTEX removal, while the interactions between benzene and ethyl benzene concentrations significantly reduced BTEX removal in mixtures.

\section{ACKNOWLEDGEMENT}

This work was supported by the research funds from the University of Ulsan, South Korea (2006).

Table 2: Analysis of variance for total RE

\begin{tabular}{llllllll}
\hline \multicolumn{1}{c}{ Source } & DF & $\begin{array}{c}\text { Seq } \\
\text { SS }\end{array}$ & $\begin{array}{c}\text { Adj } \\
\text { SS }\end{array}$ & $\begin{array}{l}\text { Adj } \\
\text { MS }\end{array}$ & F & P \\
\hline Main Effects & 4 & 1738.15 & 1738.15 & 434.537 & 5000 & 0.010 \\
2-Way Interactions & 3 & 68.37 & 68.37 & 22.788 & 284.85 & 0.044 \\
Curvature & 1 & 863.04 & 863.04 & 863.041 & 0.0001 & 0.006 \\
Residual Error & 1 & 0.08 & 0.08 & 0.080 & & \\
Pure Error & 1 & 0.08 & 0.08 & 0.080 & & \\
Total & 9 & 2669.64 & & & & & \\
& & & & & & & \\
\hline
\end{tabular}

Table 3: Statistically significant $t$ and $P$ values for total BTEX removal

\begin{tabular}{clc}
\hline Term & \multicolumn{1}{c}{$\boldsymbol{t}$} & $\boldsymbol{P}$ \\
\hline Constant & 509.75 & 0.001 \\
$\mathrm{X}_{1}$ & 99.00 & 0.006 \\
$\mathrm{X}_{2}$ & 85.75 & 0.007 \\
$\mathrm{X}_{3}$ & 63.50 & 0.010 \\
$\mathrm{X}_{4}$ & 23.25 & 0.027 \\
$\mathrm{X}_{1} \mathrm{X}_{2}$ & 5.00 & 0.126 \\
$\mathrm{X}_{1} \mathrm{X}_{3}$ & -23.25 & 0.027 \\
$\mathrm{X}_{1} \mathrm{X}_{4}$ & 17.00 & 0.037 \\
$\mathrm{Ct} \mathrm{Pt}$ & 103.87 & 0.006 \\
\hline (Concentrations: $\mathrm{X}_{1}$ : Benzene, $\mathrm{X}_{2}$ : Toluene, $\mathrm{X}_{3}$ : Ethyl-benzene, $\mathrm{X}_{4}:$ Xylene)
\end{tabular}

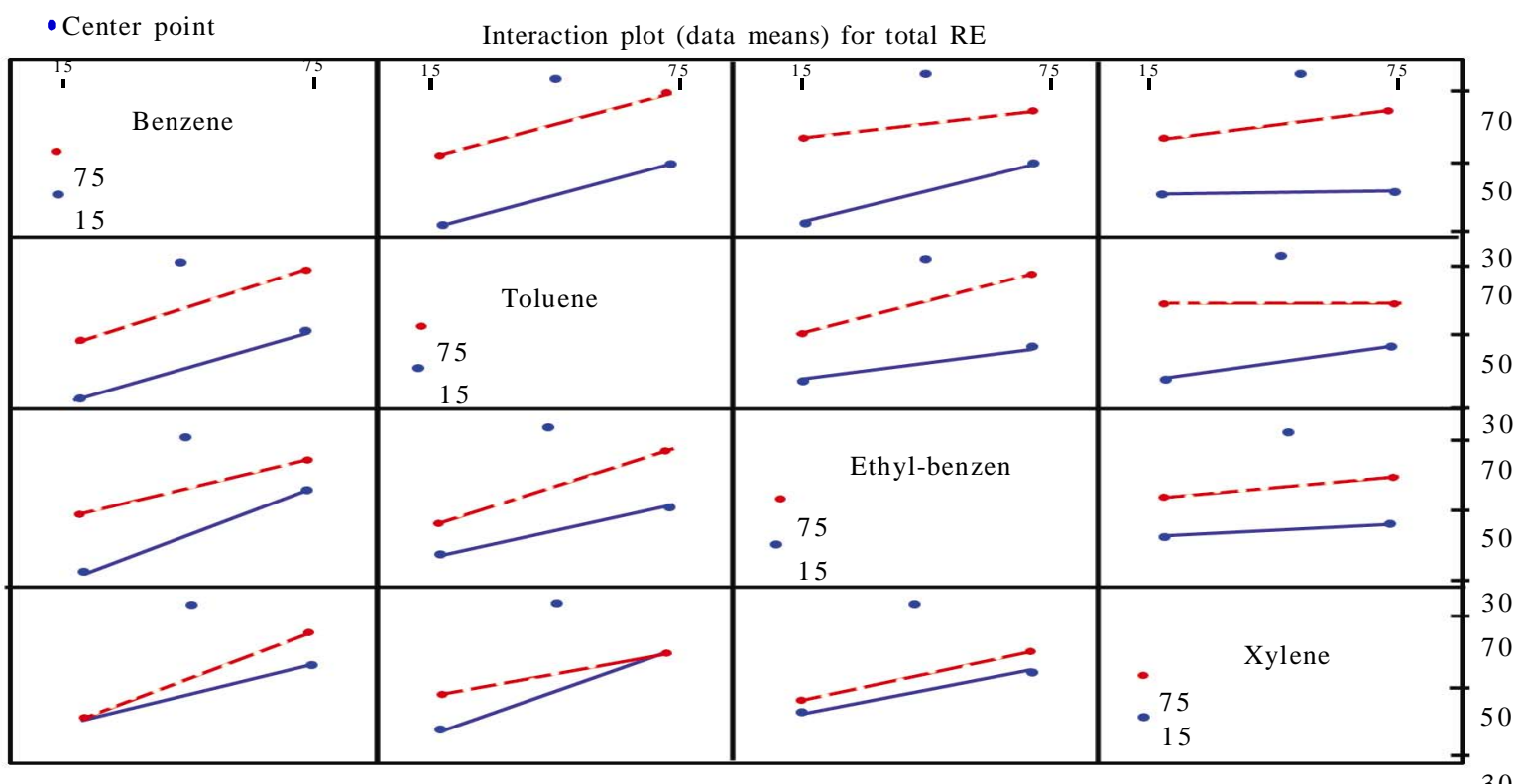

Fig 4: Interaction Plot for total BTEX removal by mixed cultures (Units: BTEX concentration, mg/L; Total-RE, \%) 


\section{REFERENCES}

Alvarez, P.J.J., Vogel, T.M., (1991). Substrate interactions of benzene, toluene and para-xylene during microbial degradation by pure cultures and mixed culture aquifer slurries., Appl. Environ. Microbiol., 57, 2981-2985.

Bahrani, A.R., Edwards, J.W., (2006). Evaluation of benzene exposure in adults and urinary s-phenylmercapturic acid in children living in Adelaide, South Australia, Int. J. Environ. Sci. Technol., 3, 113-117.

Bielefeldt, A.R., Stensel, H.D., (1999). Evaluation of biodegradation kinetic testing methods and long term viability in biokinetics for BTEX metabolism., Wat. Res., 33, 733740 .

Box, G.E., Hunter, W.G., Hunter J.S., (1978). Statistics for Experimenters., John Wiley \& Sons, Inc., New York, N.Y.

Burgess, J.E., Parsons, S.A., Stuetz, R.M., (2001). Developments in odour control and waste gas treatment biotechnology: a review., Biotech. Adv., 19, 35-63.

Chang, M.K., Voice, T.C. and Criddle, C.S., (1993). Kinetics of competitive inhibition and cometabolism in the biodegradation of benzene, toluene and p-xylene by two Pseudomonas isolates., Biotechnol. Bioeng., 41, 1057-1065. Gusmão, V.R., Martins, T.H., Chinalia, F.A., Sakamoto, I.K., Thieman, O.H., Varesche, M.B.A., (2006). BTEX and ethanol removal in horizontal-flow anaerobic immobilized biomass reactor under denitrifying condition., Proc. Biochem., 41, 1391-1400.

Haigler, B.E., Pettigrew, C.A., Spain J.C., (1992). Biodegradation of mixtures of substituted benzenes by Pseudomonas sp. Strain JS 150., Appl. Environ. Microbiol., 58, 2237-2244.

Jenkin, M.E., Clemitshaw, K.C., (2000). Ozone and other secondary photochemical pollutants: chemical processes governing their formation in the planetary boundary layer., Atm. Environ., 34, 2499-2527

Kelly, W.R., Hornberger, G.M., Herman, J.S., Mills, A.L., (1996). Kinetics of BTX biodegradation and mineralization in batch and column systems., J. Cont. Hydrol., 23, 113-132.
Khuri, A.I., Cornell, J.A., (1987). Response Surfaces: Design and Analysis., Marcel Dekker, New York.

Mackay, D., Shiu, W.Y., (1981). A critical review of Henry’s law constants for chemicals of environmental interest., J. Phys. Chem. Ref. Data., 10, 1175-1199.

Martin, M.A., Keuning, S., Janssen, D.B., (1998). Handbook on Biodegradation and Biological Treatment of Hazardous

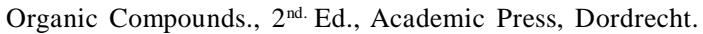

Montgomery, D.C., (1991). Design and Analysis of Experiments., third ed., Wiley, New York.

Murata, M., Tsujikawa, M., Kawanishi, S., (1999). Oxidative DNA damage by minor metabolites of toluene may lead to carcinogenesis and reproductive dysfunction., Biochem. Biophy. Res. Comm., 261, 478-483.

Oh, Y.Z., Shareefdeen, Z., Baltzis, B.C., Bartha, R., (1994). Interactions between benzene, toluene and p-xylene during their biodegradation., Biotechnol. Bioeng., 44, 533-538.

Prenafeta-Boldú, F.X., Vervoort, J., Grotenhuis, J.T.C., van Groenestijn, W.J., (2002). Substrate interactions during the biodegradation of benzene, toluene, ethylbenzene, and xylene hydrocarbons by the fungus Cladophialophora sp. Strain T1., Appl. Environ. Microbiol., 68, 2660-2665.

Rene, E.R., Raj, R., Swaminathan, T., (2001). A substrate inhibition study of microbial growth on BTX biodegradation using a mixed culture., In: Proceedings of International conference on Industrial Pollution and Control Technologies, Hyderabad, India, 643-650.

Schwarzenbach, R.P., Gschwend, P.M. and Imboden, D.M., (1993). Environmental Organic Chemistry., Wiley, Newyork, NY.

Shim, H., Yang S.T., (1999). Biodegradation of benzene, toluene, ethylbenzene, and o-xylene by a co-culture of Pseudomonas putida and Pseudomonas fluorescens immobilized in a fibrousbed bioreactor., J. Biotechnol., 67, 99-112.

Yeom, S.H., Yoo, Y.J., (1999). Removal of benzene in a hybrid bioreactor., Proc. Biochem., 34, 281-288.

\section{AUTHOR (S) BIOSKETCHES}

Rene, E.R., Ph.D., University of La Coruña, Department of Chemical Engineering, Faculty of Sciences, Campus da Zapateira, E-15071-La Coruña, Spain. Email: eldonrene@yahoo.com

Jo, M.S., Master Degree student at the Department of Civil and Environmental Engineering, University of Ulsan, South Korea. Email: upt360@nate.com

Kim, S.H., Presently the CEO of SGR Technologies, Ulsan, South Korea and also a PhD student at the Department of Civil and Environmental Engineering, University of Ulsan, South Korea.

Email: sgrtech@sgrtech.co.kr

Park, H.S., Ph.D., Professor at the Department of Civil and Environmental Engineering and Director of the Environmental Pollution Control Laboratory, University of Ulsan, South Korea.

Email: parkhs@ulsan.ac.kr

This article should be referenced as follows:

Rene, E.R., Jo, M.S., Kim, S.H., Park, H.S., (2007). Statistical analysis of main and interaction effects during the removal of BTEX mixtures in batch conditions using wastewater treatment plant sludge microbes. Int. J. Environ. Sci. Tech., 4 (2), 177-182. 